\title{
Analisis Video Likes to Video Views Ratio Youtube Pada 6 Merk HP Terbaik Dan Terlaris di Dunia Tahun 2021
}

\author{
I Made Wira Subawa
}

wirasubawa12@gmail.com

\begin{abstract}
In this world of technology, many applications are used by the public to seek knowledge or entertainment, one example is Yutube. Youtube is a video sharing website, from funny videos, news, horror and others. Where youtube was created by three former PayPal employees in February 2005. In Indonesia alone youtube has 170 million users who access the site, by looking at the existing users, there are several companies taking this opportunity to advertise or introduce their products to the public, which is expected increase sales of their products. There are 6 companies that use Youtube as a marketing tool, namely Samsung Indonesia, Apple, Xiaomi Indonesia, Oppo Indonesia, Vivo Indonesia, Huawei Indonesia. The method used for this research is quantitative exploratory method. The results of this study indicate that the smartphone vendor Oppo Indonesia is ranked first and has good account performance credibility.
\end{abstract}

\begin{abstract}
ABSTRAK
Dalam dunia teknologi ini banyak aplikasi yang di gunakan oleh masyarakat untuk mencari ilmu pengetahuan atau hiburan salah satu conto yaitu Yutube. Youtube adalah sebuah situs web berbagi video, dari video lucu, berita, horror dan lain-lain. Dimana youtube ini dibuat oleh tiga mantan karyawan PayPal pada Februari 2005. Di Indonesia sendiri youtube memiliki 170 juta pengguna yang mengakses situs tersebut, dengan melihat penngguna yang ada, ada beberapa perusahaan mengambil peluang tersebut untuk mengiklankan atau memperkenalkan produk mereka ke masyarakan, yang di harapkan meningkankan penjualan produk mereka. Ada 6 perusahaan yang memanfaatkan Youtube sebagai sarana marketing, yaitu Samsung Indonesia, Apple, Xiaomi Indonesia, Oppo Indonesia, Vivo Indonesia, Huawei Indonesia. Metode yang digunakan untuk penelitian ini yaitu metode eksploratif kuantitatif. Hasil dari penelitian ini menunjukan bahwa vendor smartphone Oppo Indonesia mendapatkan peringkat pertama dan memiliki kredibilitas performa chanel yang baik.
\end{abstract}

Keyword : Credibility Account Youtube ; Social Media Marketing ; Application Youtube ; Video Like to Video Views Ratio ; Vendor Smartphone. 


\section{PENDAHULUAN}

YouTube merupakan situs yang didirikan tiga sekawan yaitu Chad Hurley, Steve Chen, dan Jawed Karim.4 Situs ini berfungsi untuk mengunggah video yang dapat kita bagikan (share) kepada khalayak di internet. Didalamnya terdapat videovideo yang telah diunggah (upload) dan dapat kita lihat tanpa harus menunggu lama(Akbar 2018). Dalam prakteknya, pengguna situs ini tidak hanya masyarakat biasa, tapi juga media korporat semacam BBC, CBS, Hulu, Vevo, dan berbagai macam organisasi lainnya.

Dengan adanya situs Youtube ini ada beberapa brand memanfaatkannya sebagai tempat memasarkan produknya ke pada masyarakat agar lebih di kenal secara detail. Dilihat dari penggunanya youtube di Indonesia kurang lebih sebanyak 170 juta pengguna, yang di mana itu termasuk angka yang cukup besar dalam melakukan iklan pada platform ini. Cukup banyak chanel perushaan-perusahaan terkenal yang ada pada youtube, contohnya seperti vendor smartphone di Indonesia. Adapun Top 6 Vendor Smartphone di Indonesia, diantaranya yaitu : Oppo Indonesia, Samsung Indonesia, Vivo Indonesia, Xiaomi Indonesia, Realme Indonesia, Huawei Indonesia, Apple(“6 Merk HP Terbaik Dan Terlaris di Dunia Tahun 2021”).

Pada penelitian ini akan menggunakan metode eksploratif kuantitatif, dan akan menghitung menggunakan rasio-rasio yang ada pada Youtube. Pada penelitian (Hendika Permana 2021) menjelaskan bahwa terdapat 10 rasio yang ada pada Youtube dan relevan digunakan sebagai media ukur kredibilitas akun yang ada. Pada penelitian ini akan berfokus pada penghitungan pada kredibilitan Video Like to Video View Ratio pada 6 Merk HP Terbaik Dan Terlaris di Dunia Tahun 2021. Dari hal tersebut tujuan dari penelitian ini ingin mengetahui seberapa kredibilitas dari performa chanel Youtube yang dimiliki oleh setiap vendor Smartphone tersebut.

\section{TINJAUAN PUSTAKA}

Saat ini aplikasi yang digunakan pada smartphone semakin berkembang, dan berbanding lurus dengan perkembangan ilmu pengetahuan, bukan hanya orang dewasa, namun anak Taman Kanak-Kanak (TK) sudah menggunakan smartphone setiap harinya untuk mencari hiburan melalui aplikasi Youtube(Putra and Patmaningrum 2018).

Youtube merupakan sebuah platform untuk memublikasikan video, platform ini dapat diakses oleh semua orang di negara manapun. Platform ini resmi berdiri pada tahun 2005. Pendirinya adalah Chad Hurley, Steve Chen, Jawed Karim dimana mereka bertiga adalah mantan karyawan PayPal. Kemudian platform Youtube dibeli oleh Google dan diperkenalkan kembali pada tahun 2006. Berdasarkan riset yang dilakukan oleh hootsuite sangat jelas bahwa Youtube sangat digemari oleh masyarakat Indonesia, dengan menduduki most active social media. Youtube telah memudahkan miliyaran orang dalam menemukan, menonton, dan membagikan berbagai macam video. Youtube menyediakan forum bagi orang-orang untuk saling berhubungan, memberikan informasi, menginspirasi orang lain di seluruh dunia, serta bertindak sebagai platform distribusi bagi pembuat konten dan pengiklan, baik yang besar maupun kecil. Youtube menjadi pemimpin untuk situs pencarian video di internet, dengan lebih dari 100.000.000 video ditonton oleh pengunjung setiap harinya. Lebih dari 65.000 video kini diunggah setiap hari ke Youtube(Putra and Patmaningrum 2018).

Dengan pengguna youtube yang memiliki potensi untuk melakukan marketing produk, dengan melihat potensi tersebut banyak brand yang memanfaatkan hal tersebut sehingga setiap brand harus memiliki chanel tersendiri untuk mengelolah konten yang mereka buat agar menarik peminat untuk membeli produk bereka, yang dimana brand tersebut harus mengetahui kualitas 
chanel yang mereka Kelola di karenakan kualitas chanel nantinya menentukan strata maupun kredibilitas pemilik chanel. Kredibilitas chanel Youtube merupakan suatu hal yang cukup penting untuk berbagai kepentingan. Kredibilitas sebuah chanel Youtube dapat diukur dari tingkat performa yang dihasilkan secara matematis. Dalam mengukur performa diperlukan skala pengukuran yang tertuang ke dalam rasio.

\section{METODE PENELITIAN}

Penelitian ini menggunakan metode eksploratif kuantitatif untuk mengetahui kredibilitas dari performa chanel youtube dari 6 Merk HP Terbaik Dan Terlaris di Dunia Tahun 2021. Metode penelitian menggunakan metode eksploratif, yaitu untuk mencari tahu suatu kejadian tertentu atau hubungan antara dua atau lebih variable.

Tujuan dari penelitian ini dimana agar mengetahui seberapa nilai kreadibilitas dari performa chanel dari 6 brand Smartphone ada beberapa langkah yang harus dilakukan dalam penelitian ini, sehingga mampu menemukan peringkat pertama dari chanel Youtube brand smartphone. Langkah-langkah yang dilakukan pada penelitian ini, diantaranya yaitu :

1. Melakukan Eksplorasi Pada Website Untuk Menentukan Objek yang Akan Dianalisa.

Pada tahap ini kita melakukan eksplorasi ke beberapa website yang berpotensi menyediakan informasi yang banyak mengenai object yang akan di teliti nanti. Selanjutnya mencari brand-brand smartphone yang sudah di tentukan sebagai objek untuk melakukan analisis, dimana pada analisis ini berdasarkan chanel Youtube yang dimiliki dari setiap brand smartphone tersebut.

2. Menghitung Nilai Rata-Rata Variable Dari Top 5 Vendor Smartphone di Indonesia. Pada langkah ini, peneliti menghitung nilai variable video like dan variable video views dari setiap video yang ada pada chanel Youtube brand smartphone tersebut. Untuk mencari nilai tersebut terlebih dahulu mencari nilai dari setiap video lalu menghitung rata-rata dari variabel video like dan variable video views untuk menghitung nilai ratarata dengan cara mengambil minimal 10 postingan yang ada di masing-masing chanel Youtube.

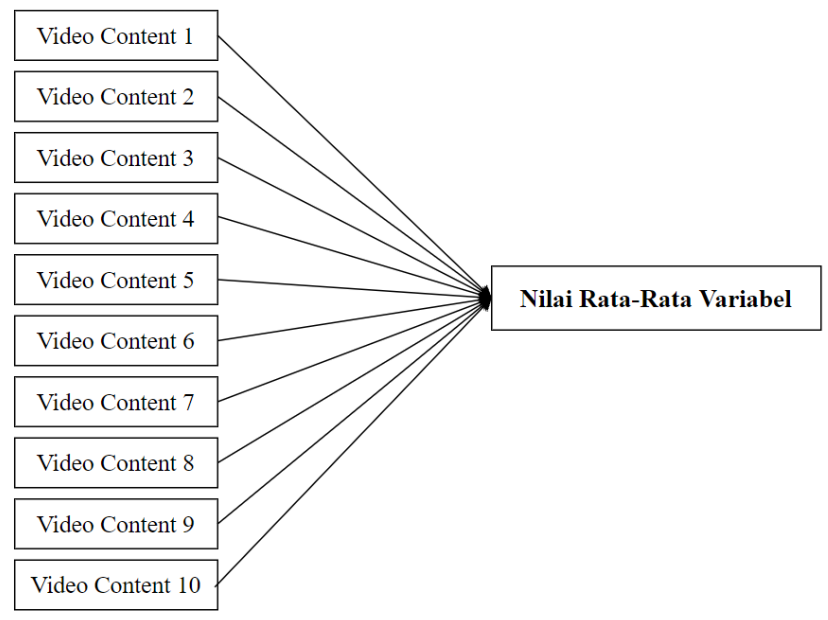

Gambar 1. Analisa Nilai Rata-Rata Variabel. 


\section{Menghitung Nilai Kredibilitas Rasio}

Setelah mendapatkan niali rata-rata dari variable video like dan variable video views, selanjutnya menghitung nilai kredibilitas. Pada tahap ini menggunakan cara membagi nilai variabel pertama dengan nilai variabel kedua. Jika video like memiliki nilai 100 dan video views memiliki nilai 300, maka cara menghitungnya yaitu $100: 300=0,3$. Dengan begitu nilai dari video comments to video views ratio adalah 0,3 .

\section{Menentukan Peringkat Pada Chanel Youtube}

Pada tahap ini dilakukannya penentuan peringkat pada masing-masing rasio, Jika karakteristik rasio merupakan rendah, maka objek yang memiliki nilai terendah akan mendapatkan angka 6 dan objek yang memiliki nilai tertinggi akan mendapatkan angka 1. Namun jika rasio memiliki karakteritik tinggi maka objek yang mendapatkan nilai tinggi akan mendapatkan angka 6 dan objek yang mendapatkan nilai terendah akan mendapatkan angka 1. Setelah mendapatkan hasil kredibilitas ratio maka dapat disimpulkan objek yang mana mendapatkan peringkat 1 sampai dengan peringkat 6 .

\section{HASIL DAN PEMBAHASAN}

Chanel Youtube dari 6 Merk HP Terbaik Dan Terlaris di Dunia Tahun 2021, diantaranya

\section{Samsung Indonesia}

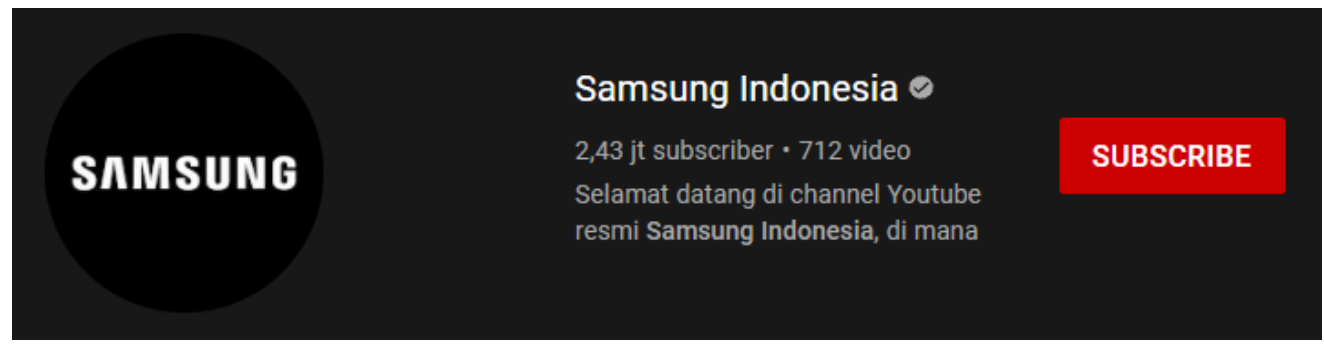

Gambar 1 Chanel Youtube Samsung Indonesia

Sumber : https://www.youtube.com/results?search_query=samsung+indonesia (akses pada 19-10-2021)

\section{Apple}

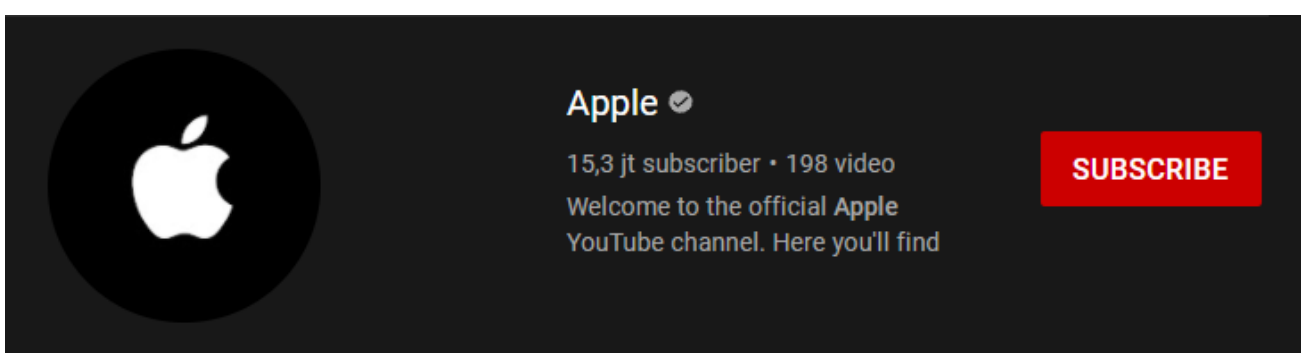

Gambar 2 Chanel Apple

Sumber : https://www.youtube.com/results?search_query=apple (akses pada 19-10-2021) 


\section{Xiaomi Indonesia}

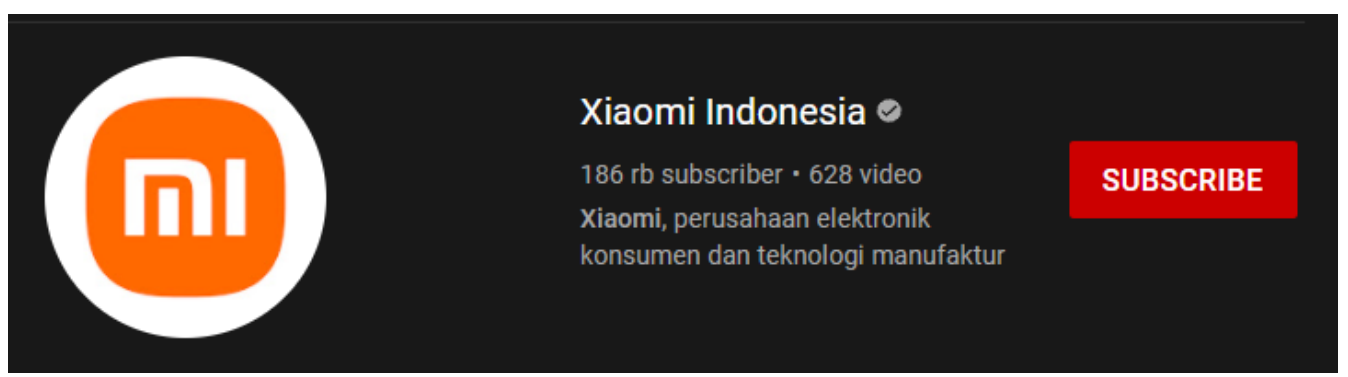

Gambar 3 Chanel Youtube xiaomi indonesia

Sumber : https://www.youtube.com/results?search_query=xiaomi+indonesia (akses pada 19-10-2021)

\section{Oppo Indonesia}

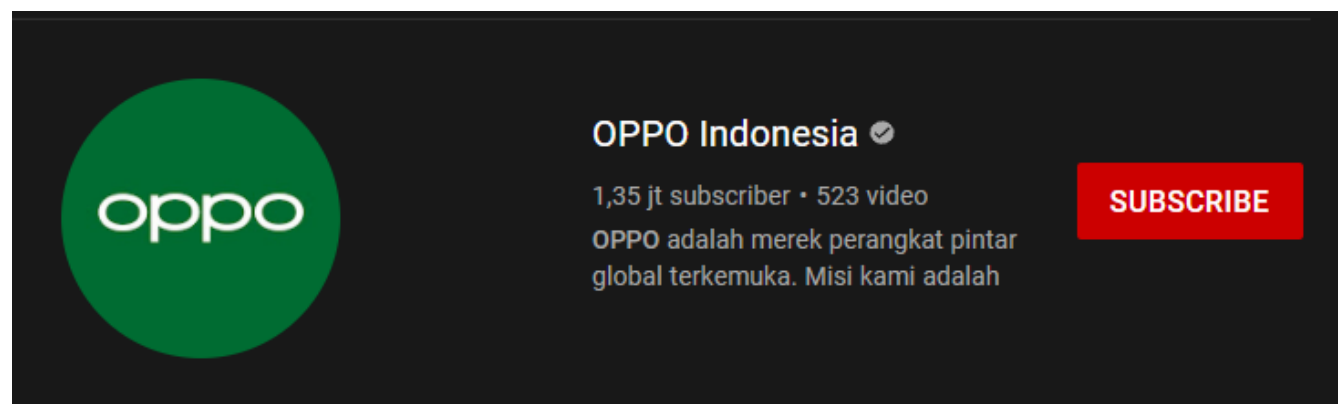

Gambar 4 Chanel Youtube Oppo Indonesia

Sumber : https://www.youtube.com/results?search_query=oppo+Indonesia (akses pada 19-10-2021)

\section{Vivo Indonesia}

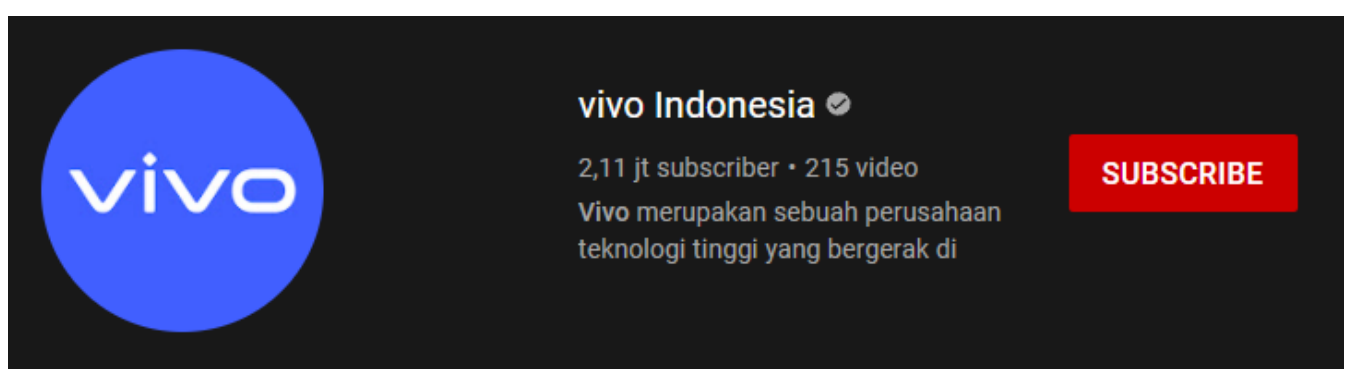

Gambar 5 Chanel Youtube Vivo Indonesia

Sumber : https://www.youtube.com/results?search_query=vivo+indonesia (akses pada 19-10-2021) 


\section{Huawei Indonesia}

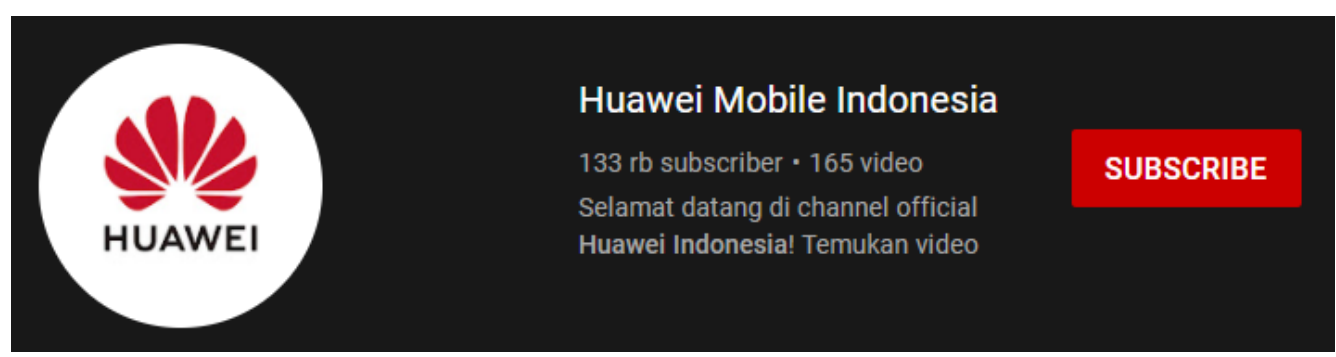

Gambar 6 Chanel Youtube Huawei Mobile Indonesia

Sumber : https://www.youtube.com/results?search_query=Huawei+Mobile+Indonesia (akses pada 19-10-2021)

Dari kelima chanel Youtube 6 Merk HP Terbaik Dan Terlaris di Dunia Tahun 2021, peneliti menemukan nilai dari masing-masing variabel yang ada untuk menghitung rasio Video Likes to Video Views Ratio dari setiap chanel. Pada chanel Youtube terdapat 7 variabel, diantaranya yaitu :

1. Likes

2. Followers

3. Following

4. Video Likes

5. Video Comments

6. Video Share

7. Video Views

Dari ketujuh variabel tersebut peneliti hanya fokus untuk menemukan hasil dari 2 variabel, yaitu :

1. Video Like

2. Video Views

Dari kedua variabel tersebut kemudian dianalisa sehingga menemukan nilai rata-rata dari variabel video like dan variabel video views. Untuk menghitung nilai rata-rata dari variabel video comments dan variabel video views yaitu dengan cara mengambil minimal 10 postingan kemudian di hitung sehingga menemukan nilai rata-rata dari masing-masing variabel. Berikut merupakan tabel nilai rata-rata dari masing-masing vendor smartphone di Indonesia, yaitu :

Table 1. Analisa Nilai Rata-Rata Nilai Variabel Video Like dan Video Views Youtube Samsung Indonesia

\begin{tabular}{|l|l|l|}
\hline No & Video Likes & Video Views \\
\hline
\end{tabular}




\begin{tabular}{|c|c|c|}
\hline 1 & 124 & 2.476 \\
\hline 2 & 197 & 5.977 \\
\hline 3 & 103 & 2.803 \\
\hline 4 & 762 & 13.813 \\
\hline 5 & 1.100 & 22.884 \\
\hline 6 & 309 & 8.219 \\
\hline 7 & 116 & 2.156 \\
\hline 8 & 2.100 & 52.355 \\
\hline 9 & 447 & 10.554 \\
\hline 10 & 659 & 9.411 \\
\hline Total & 592 & 13.065 \\
\hline
\end{tabular}

Table 2. Analisa Nilai Rata-Rata Nilai Variabel Video Like dan Video Views Youtube Apple

\begin{tabular}{|c|r|r|}
\hline No & \multicolumn{1}{|c|}{$\begin{array}{c}\text { Video } \\
\text { Likes }\end{array}$} & \multicolumn{1}{c|}{ Video Views } \\
\hline 1 & 161.000 & 1.356 .396 \\
\hline 2 & 3.900 & 95.962 \\
\hline 3 & 4.200 & 91.868 \\
\hline 4 & 173.000 & 10.883 .138 \\
\hline 5 & 22.000 & 910.114 \\
\hline 6 & 25.000 & 1.051 .711 \\
\hline 7 & 27.000 & 1.160 .610 \\
\hline 8 & 33.000 & 1.163 .889 \\
\hline 9 & 8.800 & 13.880 .633 \\
\hline 10 & 83.000 & 3.030 .193 \\
\hline Total & $\mathbf{5 4 . 0 9 0}$ & $\mathbf{3 . 3 6 2 . 4 5 1}$ \\
\hline
\end{tabular}

Sumber : Pengolah Data Excel

Table 3. Analisa Nilai Rata-Rata Nilai Variabel Video Like dan Video Views Youtube Xiaomi Indonesia

\begin{tabular}{|c|r|r|}
\hline No & Video Likes & \multicolumn{1}{c|}{ Video Views } \\
\hline 1 & 83 & 1.275 \\
\hline 2 & 70 & 1.457 \\
\hline 3 & 178 & 11.061 \\
\hline 4 & 217 & 9.863 \\
\hline 5 & 141 & 1.456 \\
\hline 6 & 247 & 4.773 \\
\hline 7 & 1.900 & 47.797 \\
\hline 8 & 230 & 3.103 \\
\hline 9 & 169 & 18.700 \\
\hline 10 & 1.000 & 716.001 \\
\hline Total & $\mathbf{4 2 4}$ & $\mathbf{8 1 . 5 4 9}$ \\
\hline \multicolumn{3}{|c}{ Sumber : Pengolah Data Excel } \\
\hline
\end{tabular}


Table 4. Analisa Nilai Rata-Rata Nilai Variabel Video Like dan Video Views Youtube Oppo Indonesia

\begin{tabular}{|c|r|r|}
\hline No & Video Likes & \multicolumn{1}{c|}{ Video Views } \\
\hline 1 & 2.305 & 63 \\
\hline 2 & 149 & 5.158 \\
\hline 3 & 24 & 239.165 \\
\hline 4 & 1.300 & 29.751 \\
\hline 5 & 100 & 121.172 \\
\hline 6 & 187 & 455.081 \\
\hline 7 & 53 & 1.731 \\
\hline 8 & 22 & 1.028 \\
\hline 9 & 53 & 1.731 \\
\hline 10 & 42 & 1.563 \\
\hline Total & $\mathbf{4 2 4}$ & $\mathbf{8 5 . 6 4 4}$ \\
\hline \multicolumn{3}{|c}{ Sumber : Pengolah Data Excel } \\
\hline
\end{tabular}

Table 5. Analisa Nilai Rata-Rata Nilai Variabel Video Like dan Video Views Youtube Vivo Indonesia

\begin{tabular}{|c|r|r|}
\hline No & \multicolumn{1}{|c|}{$\begin{array}{l}\text { Video } \\
\text { Likes }\end{array}$} & \multicolumn{1}{c|}{ Video Views } \\
\hline 1 & 66 & 1.695 \\
\hline 2 & 149 & 4.959 \\
\hline 3 & 54 & 2.335 \\
\hline 4 & 81 & 5.079 \\
\hline 5 & 7.900 & 1.667 .913 \\
\hline 6 & 394 & 95.666 \\
\hline 7 & 67 & 5.325 \\
\hline 8 & 71 & 7.243 \\
\hline 9 & 74 & 7.153 \\
\hline 10 & 4.400 & 1.162 .370 \\
\hline Total & $\mathbf{1 . 3 2 6}$ & $\mathbf{2 9 5 . 9 7 4}$ \\
\hline \multicolumn{3}{|r|}{ Sumber : Pengolah Data Excel } \\
\hline
\end{tabular}

Table 6. Analisa Nilai Rata-Rata Nilai Variabel Video Like dan Video Views Youtube Huawei Indonesia

\begin{tabular}{|c|r|r|}
\hline No & \multicolumn{1}{|c|}{ Video Likes } & \multicolumn{1}{c|}{ Video Views } \\
\hline 1 & 6 & 3.088 .393 \\
\hline 2 & 14 & 3.817 .889 \\
\hline
\end{tabular}




\begin{tabular}{|c|r|r|}
3 & 8 & 1.857 .303 \\
\hline 4 & 8 & 1.460 .687 \\
\hline 5 & 16 & 193 \\
\hline 6 & 237 & 62.527 \\
\hline 7 & 23 & 3.360 .388 \\
\hline 8 & 17 & 1.595 .526 \\
\hline 9 & 754 & 17 \\
\hline 10 & 7 & 2.995 .135 \\
\hline Total & $\mathbf{1 0 9}$ & $\mathbf{1 . 8 2 3 . 8 0 6}$ \\
\hline \multicolumn{3}{|c}{ Sumber : Pengolah Data Excel } \\
\hline
\end{tabular}

Setelah menghitung nilai rata-rata tersebut, maka akan menemukan hasil akhir nilai rata-rata dari variabel video like dan video view

Table 7. Nilai Variabel Pada Chanel Youtube 6 Merk HP Terbaik Dan Terlaris di Dunia Tahun 2021

\begin{tabular}{|c|r|r|r|r|r|r|}
\hline Variable & Samsung & \multicolumn{1}{|c|}{ Apple } & $\begin{array}{l}\text { Xiaomi } \\
\text { Indonesia }\end{array}$ & $\begin{array}{c}\text { Oppo } \\
\text { Indonesia }\end{array}$ & $\begin{array}{c}\text { Vivo } \\
\text { Indonesia }\end{array}$ & $\begin{array}{l}\text { Huawei } \\
\text { Indonesia }\end{array}$ \\
\hline Video Likes & 592 & 54090 & 424 & 424 & 1326 & 109 \\
\hline Video Views & 13065 & 3362451 & 81549 & 85644 & 295974 & 1.823 .806 \\
\hline \multicolumn{7}{|c|}{ Sumber : Pengolah Data Excel }
\end{tabular}

Pada chanel Youtube terdapat 17 rasio yang relevan digunakan untuk mengukur kredibilitas pada masing-masing chanel. Namun pada penelitian kali ini hanya berfokus untuk menghitung Video Like to Video Views Ratio. Untuk menghitung kredibilitas dari masing-masing chanel Youtube setiap vendor smartphone, peneliti menghitung dengan cara : variabel 1 akan dibagi dengan variabel 2, sehingga ditemukan hasil analisisa dari rasio tersebut.

Table 8. Hasil Perhitungan Rasio chanel Youtube

\begin{tabular}{|c|c|c|c|c|c|c|c|}
\hline No & \multicolumn{1}{|c|}{ RATIO } & Samsung & Apple & $\begin{array}{c}\text { Xiaomi } \\
\text { Indonesia }\end{array}$ & $\begin{array}{c}\text { Oppo } \\
\text { Indonesia }\end{array}$ & Vivo & $\begin{array}{l}\text { Huawei } \\
\text { Indonesia }\end{array}$ \\
\hline & $\begin{array}{l}\text { Video Likes } \\
\text { to Video } \\
\text { Views Ratio }\end{array}$ & 0,04528963 & 0,01608648 & 0,00519322 & 0,00494487 & 0,00447877 & 0,00005977 \\
\hline
\end{tabular}

Sumber : Pengolah Data Excel

Video Like to Video Views Ratio memiliki karakteristik yang tinggi, artinya semakin tinggi nilai yang dihasilkan maka semakin baik kredibilitas dari performa chanel tersebut. Untuk memberikan peringkat pada masing-masing Vendor Smartphone, peneliti memberikan angka 6 kepada vendor yang mendapatkan nilai tertinggi dan angka 1 untuk vendor smartphone yang mendapatkan nilai terendah. Berikut merupakan tabel urutan nilai yang dihasilkan oleh masingmasing vendor smartphone. 
Tabel 8. Nilai Rasio chanel Youtube Top 5 Vendor Smartphone di Indonesia Q1-2021

\begin{tabular}{|l|c|c|c|l|l|l|}
\hline \multicolumn{1}{|c|}{ RATIO } & \multicolumn{5}{|c|}{ NILAI } \\
\hline & $\begin{array}{l}\text { Samsung } \\
\text { Indonesia }\end{array}$ & Apple & $\begin{array}{l}\text { Xiaomi } \\
\text { Indonesia }\end{array}$ & $\begin{array}{l}\text { Oppo } \\
\text { Indonesia }\end{array}$ & $\begin{array}{l}\text { Vivo } \\
\text { Indonesia }\end{array}$ & $\begin{array}{l}\text { Huawei } \\
\text { Indonesia }\end{array}$ \\
\hline $\begin{array}{l}\text { Video Like to Video } \\
\text { Views Ratio }\end{array}$ & 6 & 5 & 4 & 3 & 2 & 1 \\
\hline
\end{tabular}

Sumber : Pengolah Data Excel

Dari Tabel Nilai Rasio chanel Youtube 6 Merk HP Terbaik Dan Terlaris di Dunia Tahun 2021 dapat simpulkan bahwa Samsung Indonesia mendapatkan nilai tertinggi untuk rasio Video Like to Video Views. Sedangkan chanel Youtube Huawei Indonesia mendapatkan nilai terendah untuk rasio ini. Jadi, pada penelitian ini Samsung Indonesia memiliki kredibilitas performa yang lebih baik dibandingkan dengan vendor smartphone yang lainnya.

\section{KESIMPULAN}

Dari hasil penelitian di atas dengan tujuan mengetahui kredibilitas performa dari chanel Youtube 6 Merk HP Terbaik Dan Terlaris di Dunia Tahun 2021 menggunakan Variabel Video Likes to Video Views Ratio. Dari 6 Merk HP Terbaik Dan Terlaris di Dunia Tahun 2021 tersebut diantaranya : Samsung Indonesia, Apple Indonesia, Xiaomi Indonesia, Oppo Indonesia, , Vivo Indonesia dan Huawei Indonesia. Dari keenam vendor smartphone tersebut dapat disimpulkan bahwa :

1. Peringkat pertama diraih oleh brand Samsung Indonesia dengan nilai tertinggi yaitu 0,04528963

2. Peringkat kedua diraih oleh brand Apple Indonesia dengan nilai 0,01608648

3. Peringkat ketiga diraih oleh brand Xiaomi Indonesia dengan nilai 0,00519322

4. Peringkat keempat diraih oleh brand Oppo Indonesia dengan nilai 0,00494487

5. Peringkat kelima diraih oleh brand Vivo Indonesia dengan nilai terendah yaitu 0,00447877

6. Peringkat keempat diraih oleh brand Huawei Indonesia dengan nilai 0,00005977 


\section{DAFTAR PUSTAKA}

Akbar, Ali. 2018. "Efektifitas Youtube Sebagai Media Penyebaran Informasi (Studi Pada Serambi on TV)." Efektifitas YouTube Sebagai Media Penyebaran Informasi (Studi Pada Serambi on TV 16 (02): 1-112. https://repository.arraniry.ac.id/id/eprint/5845/4/Ali Akbar.pdf.

Hendika Permana, I Putu. 2021. "Analisis Rasio Pada Akun Youtube Untuk Penelitian Kualitatif Menggunakan Metode Ekploratif.” Jurnal Ilmiah Media Sisfo 15 (1): 40. https://doi.org/10.33998/mediasisfo.2021.15.1.970.

Putra, Asaas, and Diah Ayu Patmaningrum. 2018. "Pengaruh Youtube Di Smartphone Terhadap Perkembangan Kemampuan Komunikasi Interpersonal Anak.” Jurnal Penelitian Komunikasi 21 (2): 159-72. https://doi.org/10.20422/jpk.v21i2.589. 